\title{
EDITORIAL
}

\section{The Future of Sudden Cardiac Death}

\author{
Henry Greenberg, M.D.
}

From the Department of Medicine, Division of Cardiology, Columbia University College of Physicians and Surgeons, St. Luke's Roosevelt Hospital, New York, NY

Cardiologists deal with sudden cardiac death incrementally, learning from each new patient and each new study. The opportunity to coorganize two symposia on this topic separated by 26 years ${ }^{1,2}$ gave me the opportunity to look from afar at what has changed and to think about where we are going. The implantable defibrillator was introduced clinically in 1980, and genes were not listed in the index of our 1982 publication. Morphological studies of the conducting system and risk stratification by stress testing were part of the mix.

Sudden cardiac death research has been transforming but is now at a breakpoint in its trajectory toward mechanistic understanding and ultimately even mastery. There are three distinct risk groups for cardiac sudden deaths. The one in the headlights now is the desperately sick heart for which an ICD offers the best outcome. This field has evolved rapidly in the past few years and the technology is becoming more responsive and more sophisticated. This category of the patients however, encompasses at most $30 \%$ of sudden cardiac death victims,${ }^{3}$ more likely $15-20 \%$. The second group of sudden cardiac death patients includes those whose entities are now understood to be managed by faulty genes. The list of diseases is long, but the total contribution to sudden cardiac death is small. The third class is that in which the patients or the victims have little or no known disease. This category however, is responsible for $80-85 \%$ of all sudden deaths.
For the first two of these groups, those patients with poorly functioning hearts and those with a gene driven arrhythmia potential, we are at a plateau. We can identify clinically patients with poor ejection fractions, determine etiology, and offer effective care with an ICD with or without CRT. ${ }^{4-6}$ We need to learn how to identify those with hearts too well to benefit from such expensive interventions and those too sick to benefit, but we will do this. From this plateau, the forward look is to find new methodologies to improve ventricular function whether with stem cells that stimulate new muscle growth, stimulants for angiogenesis, or genuinely effective antiarrhythmic medications, beyond the Cardiac Arrhythmia Suppression Trial (CAST) model. ${ }^{7}$ The research enterprise is robust; the ICD would seem to have a discrete but crucial life span, although announcing its demise is premature.

For the gene driven syndromes, we have also reached a plateau. High and low risk sub-groups within such entities as the Brugada syndrome, ${ }^{8}$ long and short QT syndromes, ${ }^{9,10}$ and hypertrophic cardiomyopathy ${ }^{11}$ are now well understood. Such discriminating insights will no doubt emerge for other syndromes such as arrhythmogenic right ventricular dysplasia and catecholaminergic polymorphic ventricular tachycardia. ${ }^{12-14}$ We then will know which patient to offer ICDs and which not to. The next step is to go beyond electrical intervention that deals with events after they have occurred.

Address for reprints: Henry Greenberg M.D., Division of Cardiology, St. Luke's Roosevelt Hospital, Suite 3B-30, 1000 10th Ave., New York, NY 10019. Fax: 212 523-7765; E-mail:hmg1@columbia.edu

Conflicts of interest: none. 
New emerging drugs such as PTC 124 that repair nonsense genes and could repair gene-driven channel proteins so as to elicit normal function would obviate any need for mechanical intervention. ${ }^{15}$ Such a drug, yet untested in cardiovascular settings, can serve as a template for what may well emerge. The future is likely to offer ICD-free therapy for all of these conditions.

The third and largest group is primarily a coronary population with preserved left ventricular function, well stratified by the iconic Myerburg classification of 1998 into three categories ${ }_{1}^{16}$ those with known coronary disease but well preserved left ventricular function, those with known risk factors but no disease, and those with no evidence, or knowledge, of either. What is the intervention here, recognizing that the incidence is very low? There are no procedures or pills. The best and currently only recourse is prevention. Public health initiatives supported by medical interventions such as statins, antihypertensive therapy, and diabetes management for appropriate patients can have a profound effect on both sudden and non-sudden mortality. Does this mean there is no room for research aimed specifically at sudden coronary death within this vast population? Not quite. Research directions that focus on reducing sudden death not slowing the progression of atherosclerosis can be labeled: genes, plaques, and scars.

Genes: Much of the propensity for coronary disease is gene driven. We have known this for lipid disorders for 50 years. But even a propensity for VT/VF post MI may be influenced by genetic likelihood. ${ }^{17,18}$ As more and more of the genetic fabric is revealed, for both coronary risk factors, with many new ones to be added to today's list, it is not hard to imagine that genetic screening for coronary disease will identify patients at risk for which interventions and prevention can be designed. ${ }^{19}$ In fact, the routine annual physical of the future will no doubt include gene panels to identify areas for preventive action.

The vulnerable plaque: This latticework of genetically determined compounds is being explored in wondrous detail ${ }^{20}$ and assumed success will permit tailored initiatives for enhancing plaque stability or reducing plaque formation or dissolving precursor lesions. Interventions here may well be plaque specific and not aimed at overall coronary prevention.

Scar: It has long been known that electrical heterogeneity introduced by scar and fibrous tissue can trigger fatal arrhythmias. Currently, the patient is subjected to ablation if they are at high risk $_{,}{ }^{21}$ but with new imaging techniques, patients can be identified early and medical or genetic interventions can be initiated to replace scar tissue or render it electrically inert. ${ }^{22}$

Twenty-five years ago the research direction of sudden death research was centered on recognition and definition of high-risk groups, with electrical instability (the PVC), coronary spasm, platelet function and autonomic system dysfunction all being considered. Today the focus is on directed treatment interventions centered on sophisticated mechanism-based risk stratification insights. Tomorrow we will prevent rather than treat the offending arrhythmia with novel reparative, genetic, and preventive strategies. But, even tomorrow there will continue to be a need for a voice, in minor key perhaps, to praise it. ${ }^{23}$

\section{REFERENCES}

1. Greenberg HM, Dwyer EM Jr., (eds). Sudden Coronary Death, Annals NY. Acad Sci 1982;382:1-484.

2. Greenberg H. Sudden cardiac death: An essay for 2008. Progress Cardiovasc Dis 2008;50:384-389.

3. Stecker EC, Vickers C, Waltz J, et al. Population-bases analysis of sudden cardiac death with and without left ventricular systolic dysfunction. J Am Coll Cardiol 2006;47:1161-1166.

4. Moss AJ, Zareba W, Hall JW, et al. Prophylactic implantation of a defibrillator in patients with myocardial infarction and reduced EF. New Engl J Med 2002;346:877-883.

5. Bardy GH, Lee KL, Mark DB, et al. (SCH-Heft) Amiodarone or an implantable cardioverter-defibrillator for congestive heart failure. N Engl J Med 2005;352:225-237.

6. Moss AJ, Brown MW, Cannom DS, et al. Multicenter automatic defibrillator trial-cardiac resyncrhonization therapy (madit-crt) design and clinical protocol. Ann Noninvasive Electrocardiol 2005; 10:34-44.

7. Greenberg HM, Hochman JS, Steinberg JS, et al. CAST investigators. Interaction of ischemia and encainide/flecainide treatment: A proposed mechanism for the increased mortality in CAST I. British Heart J 1995;74:631-635.

8. Benito $B$, Brugada $R$, Brugada J, et al. Brugada syndrome. Progress Cardiovasc Dis 2008;51:1-23.

9. Schwartz PJ, Priori SG, Spazzolini C, et al. Genotypephenotype correlations in the long-QT syndrome: Genespecifc triggers for life threatening arrhythmias. Circulation 2001;103:89-95.

10. Brugada $R$, Hong $K$, Dumaiane $R$, et al. Sudden death associated with short-QT syndrome linked to mutations in HERG. Circulation 2004;109:30-35.

11. Richard $P$, Charron $P$, Carrier L, et al. Hypertrophic cardiomyopathy: Distribution of disease genes, spectrum of mutations, and implications for a molecular diagnosis strategy. Circulation 2003;107:2227-2232.

12. Priori S, Napolitano C. Role of genetic analysis in cardiology. Part 1: Mendelian diseases: Cardiac channelopathies. Circulation 2006;113:1130-1135.

13. Muthappan $P$, Calkins H. Arrhythmogenic right ventricular dysplasia. Progress Cardiovasc Dis 2008;51:31-44. 
14. Liu N, Ruan Y, Priori SG. Catecholaminergic polymorphic ventricular tachycardia. Progress Cardiovasc Dis 2008;51:23-31.

15. Welch EM, Barton ER, Zhua J, et al. PTC124 targets genetic disorders caused by nonsense genes. Nature 2007;447:8791.

16. Myerburg RJ, Mitrani $\mathrm{R}$, Interoian $\mathrm{A} \mathrm{Jr}$, et al. Interpretation of outcomes and antiarrhythmic clinical trials: Design features and population impact. Circulation 1998;97: 1514-1521.

17. Dekker LRC, Bezzina CR, Henriques JPS, et al. Familial sudden death is an important risk factor for primary ventricular fibrillation. Circulation 2006;114:1140-1145.

18. Kaikkonen KS, Kortelainen M, Linna E, et al. Family history and the risk of sudden cardiac death as a manifesta- tion of an acute coronary event. Circulation 2006;114:14621467.

19. Prutkin JM, Sotoodehnia N. Genetics of sudden cardiac arrest. Progress Cardiovasc Dis 2008;50:390-403.

20. Virmani R, Narula J, Leon MB, Willerson JT (eds). The Vulnerable Atherosclerotic Plaque: Strategies for Diagnosis and Management. Blackwell Futura, Malden MA 2007.

21. Stevenson WG, Soejima K. Catheter ablation for ventricular tachycardia. Circulation 2007;115:2750-2760.

22. DETERMINE: Defibrillators to Reduce Risk by Magnetic Resonance Imaging Evaluation. Kadish A., Principal investigator; St. Jude Medical, Sponsor.

23. Greenberg H. In praise of sudden death. In Greenberg HM, Dwyer EM Jr (eds). Sudden Coronary Death. Annals New York Acad Sci 1982;382:181-183. 